\title{
PRSEUS Structural Concept Development
}

\author{
Alex Velicki ${ }^{1}$ \\ Boeing Research and Technology Group, Huntington Beach, CA, 92647 \\ Dawn Jegley ${ }^{2}$ \\ NASA Langley Research Center, Hampton, VA, 23681
}

\begin{abstract}
A lighter, more robust airframe is one of the key technological advancements necessary for the successful launch of any large next-generation transport aircraft. Such a premise dictates that considerable improvements beyond current state-of-the-art aluminum structures is needed, and that improvements of this magnitude will require an extensive use of composite materials that are not only lightweight, but also economical to produce. To address this challenge, researchers at NASA and The Boeing Company are developing a novel structural concept called the Pultruded Rod Stitched Efficient Unitized Structure (PRSEUS) under the Environmentally Responsible Aviation (ERA) Project. It is an integrally stiffened panel concept that is stitched together and designed to maintain residual load-carrying capabilities under a variety of damage scenarios. In addition to improved structural performance, an important facet of this unique arrangement of stitched carbon fibers is its innovative manufacturing method that has the potential to lower fabrication costs by eliminating fasteners and autoclave cures. The rationale and development status for this new approach forms the basis of the work described in this paper. The test specimens described herein were fabricated, or are currently being fabricated, by The Boeing Company, while the structural analyses and testing tasks are being performed by NASA and Boeing personnel.
\end{abstract}

\section{Nomenclature}

$\begin{array}{ll}B V I D & =\text { barely visible impact damage } \\ D L L & =\text { design limit load } \\ D S D & =\text { discrete source damage } \\ D U L & =\text { design ultimate load } \\ E A & =\text { section modulus } \\ E I & =\text { section stiffness }\end{array}$

\section{Introduction}

$\mathrm{T}^{\mathrm{s}}$

gain a competitive advantage in the marketplace, next-generation transport aircraft typically aim to achieve $20 \%$ better operating efficiency than incumbent designs. New airframe architectures, where improvements beyond aluminum structures can be achieved with the introduction of lightweight composite materials, are a significant contributor to the overall efficiencies of these new designs. Although lighter, the economic utility of composite primary structures is often diluted by their higher fabrication costs. Development of a new composite architecture that is not only inexpensive to fabricate, but also structurally superior, is the basis on which any next-generation composite structure will be judged. The fundamental premise of improving structural performance while simultaneously reducing fabrication costs forms the basis of how the design, manufacturing, and testing activities for the PRSEUS concept are being executed by NASA and Boeing researchers. A summary of this on-going work is described in the following sections.

\footnotetext{
${ }^{1}$ Principal Design Engineer, The Boeing Company, Advanced Structures R\&D, Associate Fellow, AIAA.

${ }^{2}$ Senior Aerospace Engineer, Structural Mechanics and Concepts Branch, Associate Fellow, AIAA.
} 


\section{Design Approach}

The PRSEUS panel concept (Fig. 1) is a combination of dry carbon warp-knit fabric, pultruded rods, foam core, and stitching threads that are brought together in a unique manner to create a stiffened panel geometry that utilizes resin infusion and out-of-autoclave curing to reduce recurring fabrication costs below what would be possible using traditional composite manufacturing practices. The resulting panels are one-piece unitized assemblies with seamless cocured interfaces that are reinforced with through-thickness stitching to preserve the orthotropic nature and continuity of the carbon fiber tows. ${ }^{1}$

Structural continuity is maintained by eliminating mechanical attachments, gaps, and mouse holes to provide uninterrupted load paths between the skin, stringer, and frame elements, see Fig. 2. Load paths at the stringer-to-frame intersection are maintained in both directions by passing the rod-stiffened stringer through a small keyhole in the frame web while keeping both frame caps continuous. The high-modulus rod embedded in the stringer cap increases the local strength

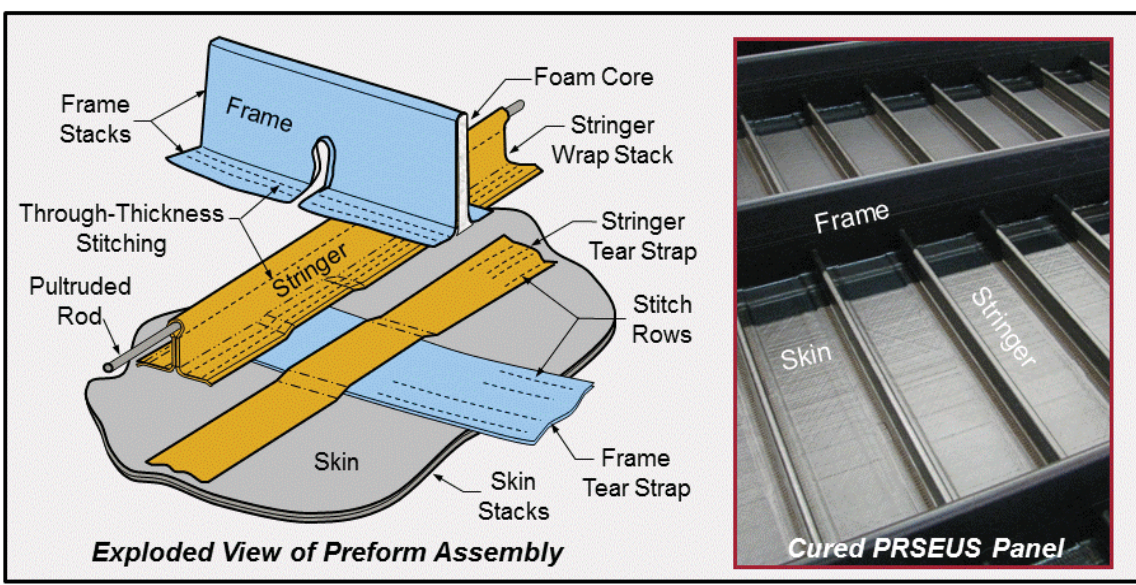

Figure 1. PRSEUS unitized structural concept.

and stability of the stringer section, while simultaneously shifting the neutral axis away from the concentrated material near the skin. Frame members are stitched directly onto the skin to eliminate shear tie details and are designed to take advantage of carbon fiber tailoring by placing bending and shear conducive lay-ups where they are the most effective. Since all of the interfaces are stitched together to provide through-thickness strength, a higher degree of fiber tailoring is possible even with composite material systems which are known to be brittle, layered, and prone to delamination., ${ }^{2,3}$

This unprecedented level of panel integration (Fig. 3) is enabled by the use of dry material forms, single-sided stitching, and the unique self-supporting preform design that is used to eliminate internal moldline cure tooling. Using these technologies, complicated stitched preforms can be fabricated without exacting tolerances, and then accurately net-molded in a single oven cure operation using high precision outer moldline tooling. Since all of the materials in the stitched assembly are dry, there are no out-time or autoclave limitations as in prepreg systems, which can restrict the size of an assembly because it must be cured within a limited processing envelope. Resin infusion is accomplished using a soft tooled fabrication scheme where the bagging film conforms to the inner moldline surface of the preform geometry and seals against a rigid outer moldline tool, thus eliminating costly

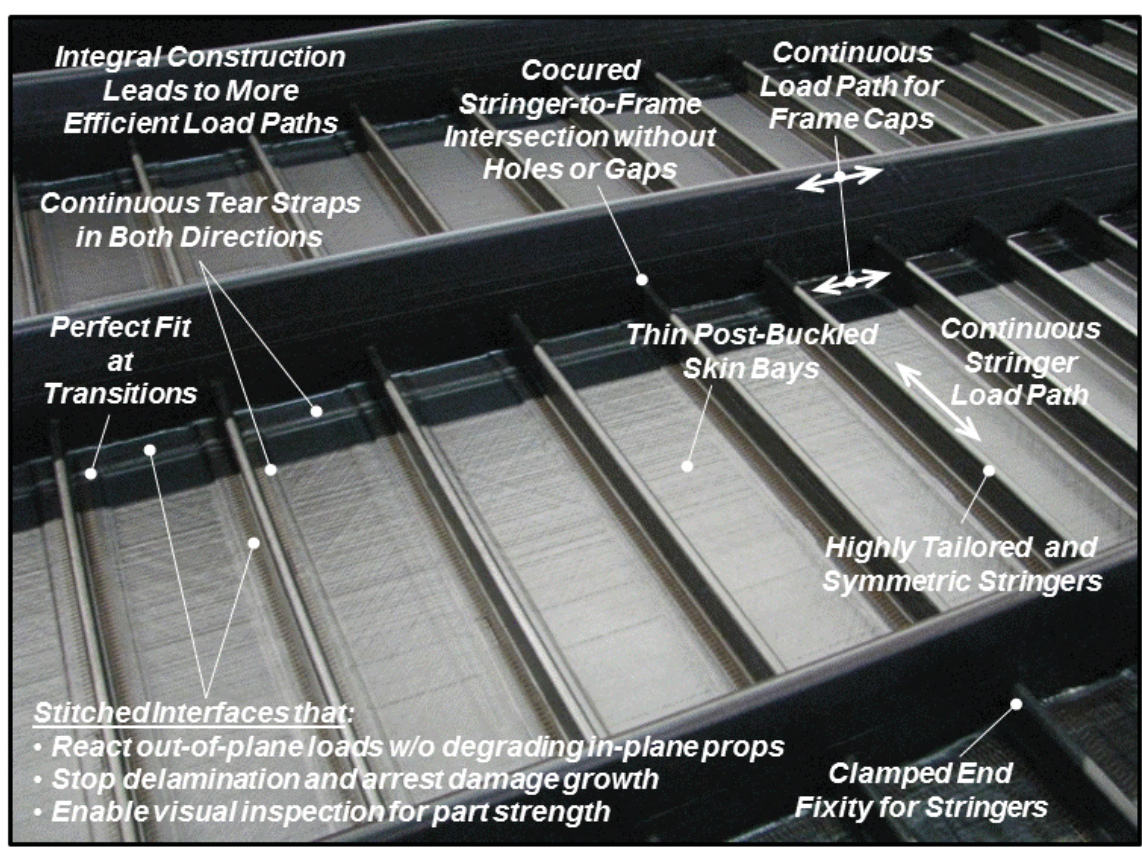

Figure 2. Structural advantages of PRSEUS panel construction. 
internal tooling that would normally be required to shape the interior details.

The manufacture of multiple PRSEUS panels has demonstrated that the self-supporting preform that eliminates interior mold tooling is feasible for the basic types of airframe geometries that have been fabricated to date. The processing parameters developed in the laboratory are scalable to larger more complex panel geometries, as were increasing levels of panel integration beyond just the stringers and frames. (Fig. 4) Solid integral cap features have also been incorporated into the panel assemblies to facilitate joining of large panels without the extensive use of fittings and fasteners.

Beyond the obvious structural and operational benefits listed in Figure 5, one of the most intriguing aspects of this new approach is the utilization of stitching to arrest and control damage propagation within the layered material system. By strategically placing stitch rows along the key structural interfaces, traditional resin-dominated failure modes can be eliminated so that the optimum strength of the panel can be more nearly realized when fiber-dominated failure modes are facilitated prior to local resin failures. Using through-thickness stitching to locally reinforce the z-direction interfaces not only makes integral construction possible, it also enables a new type of damage-arrest and

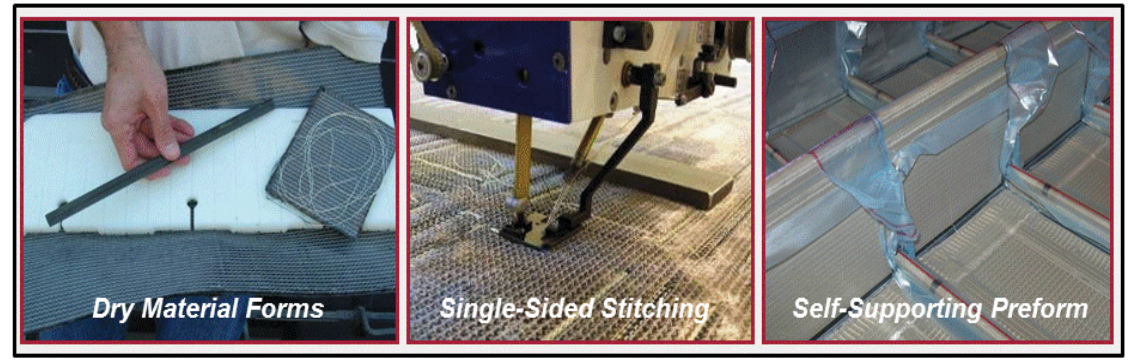

Figure 3. Fundamental technologies used to build PRSEUS panels.

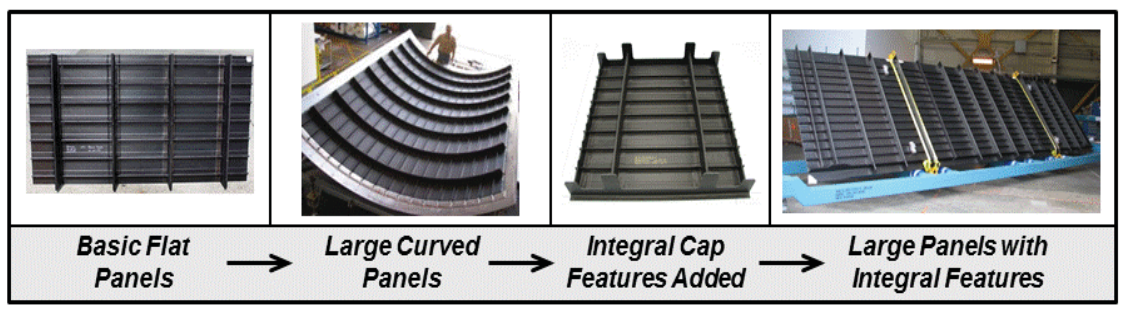

Figure 4. Increasing levels of panel integration, complexity, and size.

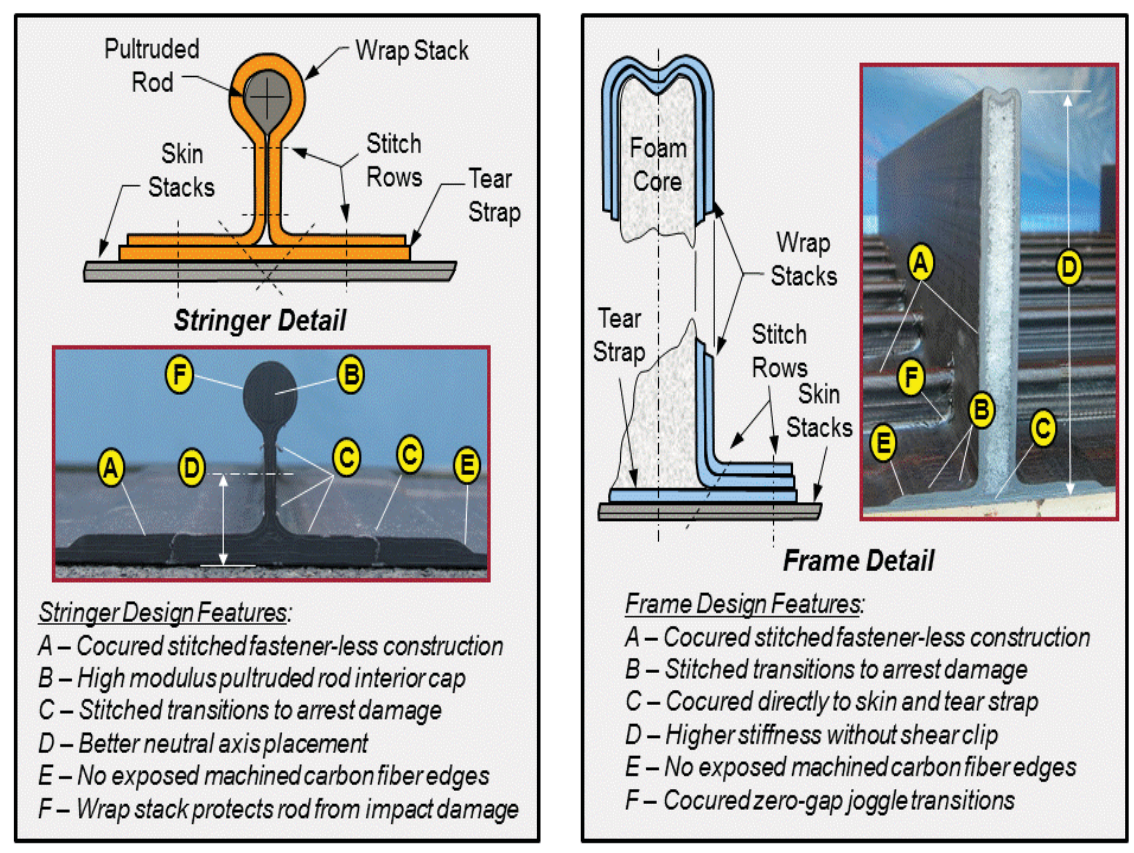

Figure 5. Summary of PRSEUS integral construction benefits. fail-safe redundancy into the structure that was previously reserved for ductile materials and not normally associated with brittle composite systems. ${ }^{4-6}$

\section{Development}

The emphasis of the development work has been to assess the fundamental loading capability and unique structural advantages of the PRSEUS panel construction. Large-notch and repair specimens were evaluated under tension loading, stringer and frame stability specimens were tested under compression loading, and special features were assessed in the areas of acoustics, ultrasonic inspection, integral cap joining, and rod-to-wrap adhesion. In parallel with these activities, a series of manufacturing and processing activities were undertaken to facilitate the fabrication of increasingly larger panels. A summary of these activities is described in the following sections and is also accompanied with a detailed reference list where more thorough discussions can be found for each topic. 


\section{A. Demonstrating Damage-Arrest Characteristics}

The transformational aspect of the stitched interface is that it provides the capability to stop damage propagation within a brittle material system, which then permits the undamaged regions of the structure to continue bearing load. Such an approach is similar to the characteristic redundancy in a metallic structure that is designed to accommodate yielding and load redistribution prior to failure. To demonstrate how these phenomena could work using stitched interfaces, a series of building-block tests (Fig. 6) was completed. ${ }^{7-12}$

The characteristic crack turning-and-arrest failure mode was first observed in a series of flat tension coupons with stitched and unstitched laminates (Fig. 7). As tension loads were increased in the stitched coupons, damage emanating from a centerline slot was first arrested horizontally at the vertical stitch row. Then as the crack turned vertically, it split the 0 -degree fibers before

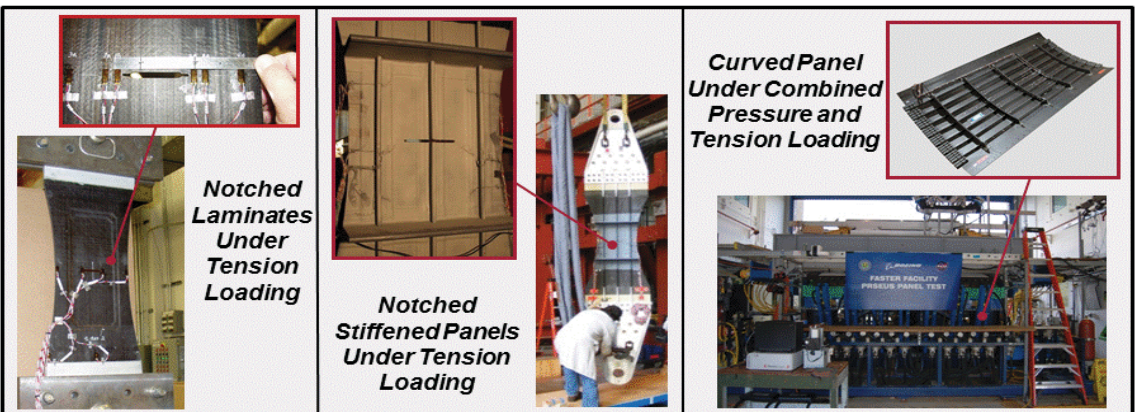

Figure 6. Testing to demonstration PRSEUS damage-arrest characteristics. it was arrested again at the horizontal stitch row. Once the damage was stopped in the opposite corners of the skin bay, increasing load levels caused the specimen to fail in the upper corner location (labeled as "Primary Failure" in the far right photo of Figure 7). Subsequent testing of unstitched configurations proved that this complex crack-turning failure mode could not be replicated without stitching, as the unstitched specimens failed horizontally across their net sections (labeled as "Primary Failure" in the far left photo of Figure 7).

Since the only difference between the two specimens was the stitching, it was evident that the peak stresses at the crack tip were no longer capable of advancing the crack front beyond the vertical stitch row. This remained true even as the loading was increased, until the crack zone expanded in the vertical direction, along the stitch row, until it reached the horizontal stitching where it was once again arrested. Under increasing load, the final failure occurred at this location. This simple test demonstrated that the fundamental damage-arrest design approach was possible using stitching and that further testing was warranted with larger more complex test

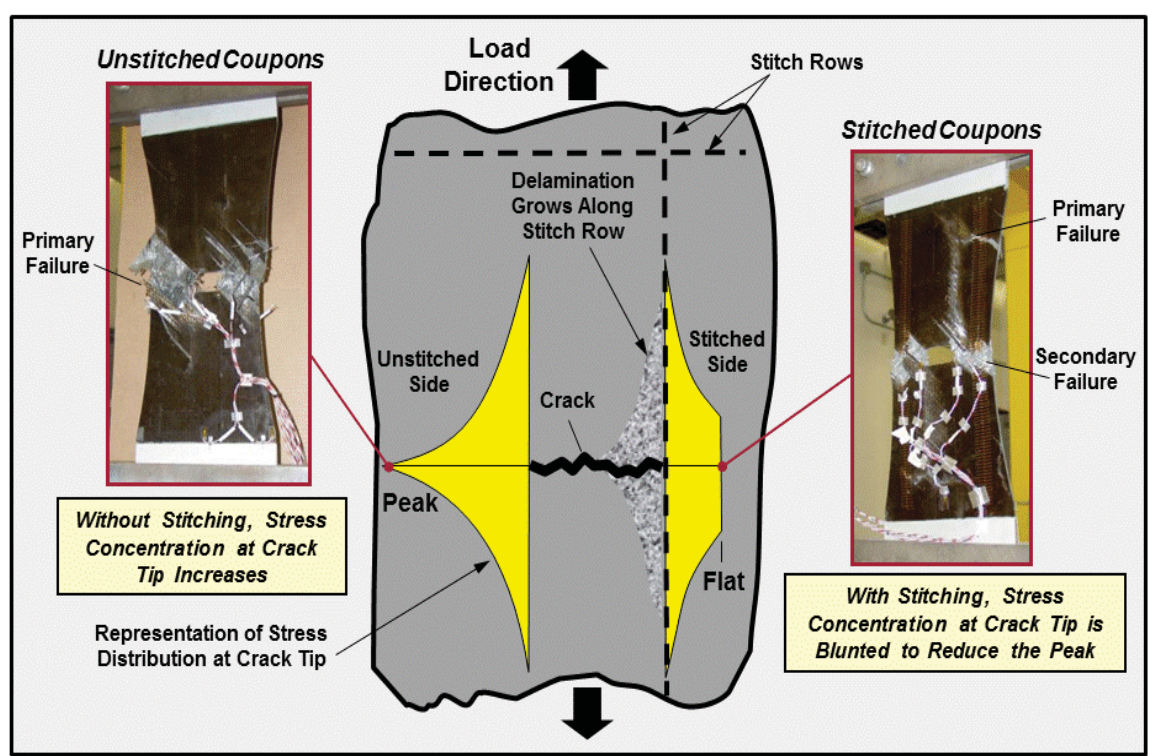

Figure 7. Stitching blunts stress concentration at crack tip. specimens.

Next, the damage-arrest design philosophy was demonstrated using a 3-stringer tension panel with 6-inch stringer spacing and 20-inch frame pitch. The goal of this test was to show that damage propagating from the center cut slot would be arrested first by the stringer flange stitching, and then again later at the frame flange stitch row. The specimen (Fig. 8) was statically loaded to failure and was able to arrest damage in both the horizontal and vertical directions as the damage propagated from the saw cut. Because damage was fully contained within the 2-bay damage zone bordered by the adjacent stringers and frames, the panel was able to continue carrying load well beyond the Discrete Source Damage (DSD) test goal set for 100\% Design Limit Load (DLL). 
With the undamaged regions of the panel working to their full capability, the final failure occurred near the frame at $132 \%$ of DLL. Without stitching, it is doubtful that the load level would have increased much beyond $82 \%$ DLL when damage first reached the stringer flange. Nevertheless, by using stitching to arrest damage and turn cracks, a more favorable internal load distribution was established that unloaded the crack tip and stopped damage from progressing beyond the stitch rows until the fibers in the undamaged regions of the panel could be loaded to failure.

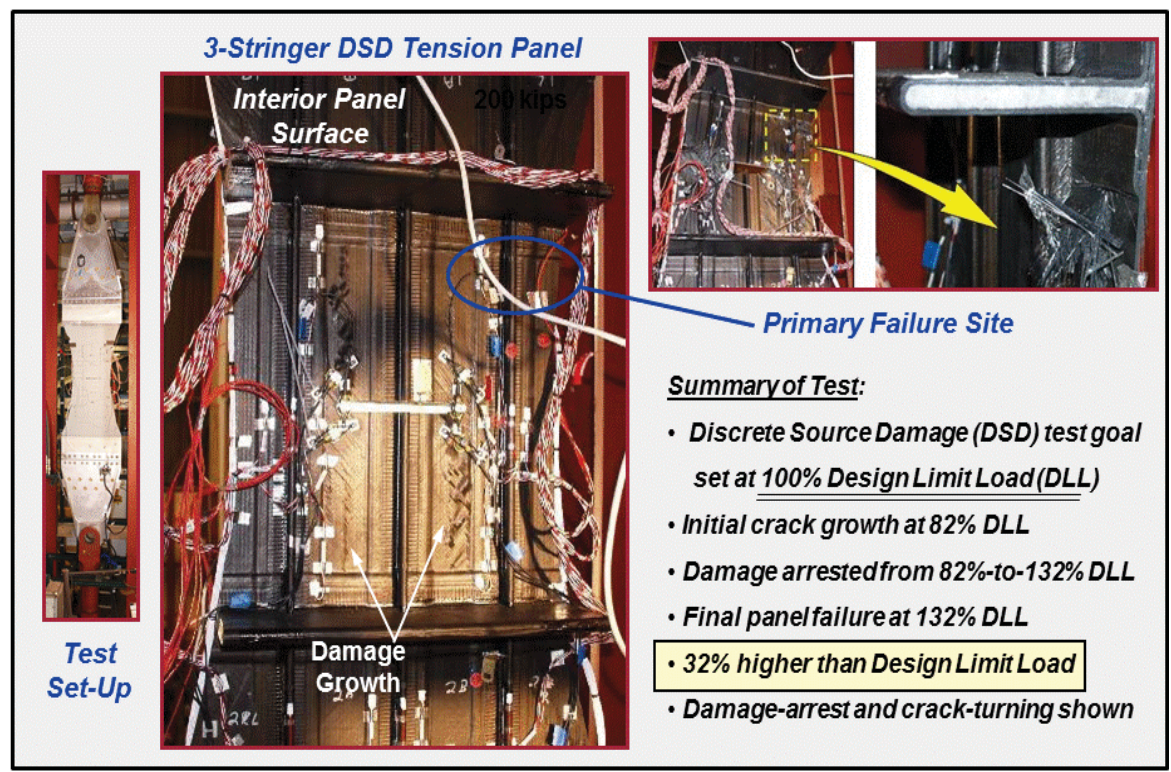

Figure 8. Damage-arrest design demonstrated on flat 3-stringer panel.

Similar testing was also completed on a large curved 7-stringer 5-frame specimen (Fig. 9) subjected to combined internal pressure and axial loading. ${ }^{8-11}$ Similar favorable damage-arrest and crack-turning phenomena were observed in this test before the specimen failed at $185 \%$ of DLL in the grip region of the specimen. The large increase in loading between the initial crack growth and final panel failure load demonstrates the robust nature of the stitched interfaces and how high levels of residual panel strength can be achieved through a combination of stitching and highly tailored laminates.

The capability to definitively stop and redirect laminate cracking, separation, and splitting plays an important role in the PRSEUS panel design approach because it reduces the design sensitivity to large-notch loading conditions. By limiting the size of damage progression and by reducing the stress

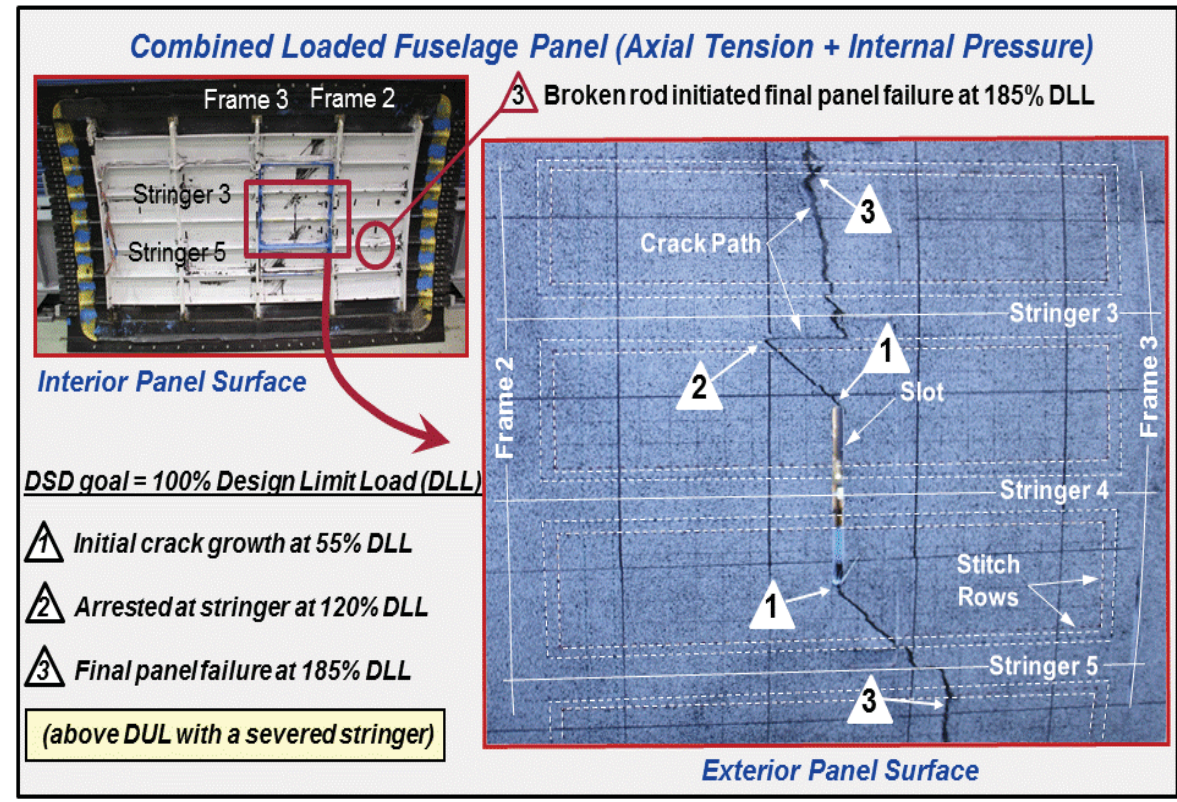

Figure 9. Damage-arrest design demonstrated on curved 7-stringer panel. intensity at the crack tip, the remaining undamaged structure is able to operate at its full design capability. While this behavior was an important aspect for meeting the design limit load requirements set for the large notch testing, it is also relevant for meeting the design ultimate load (DUL) conditions; specifically for the barely-visible impact damage (BVID), or small-notch design sizing conditions.

Common composite design practice is to achieve DUL in the BVID condition without detrimental damage growth by employing a conservative no-growth design criteria. Because of the robust nature of a stitched interface, a PRSEUS panel could be designed more aggressively, wherein damage is allowed to grow at lower load levels but is then arrested at stitch rows to maintain overall panel integrity up to DUL. 
Such an approach is outlined in Figure 10, and is predicated on a robust panel design with $100 \%$-reliable crack arrestment and turning capabilities, as has been demonstrated in PRSEUS panel testing to date. The other important attribute is that the load magnitude of the final panel failure is significantly greater than the load magnitude of the initial damage growth. As depicted in Figure 11, this theoretical difference must correspond to at least 1.5 times greater for this scheme to work. Exceeding this difference is relatively easy with stitching because the damage growth can always be stopped by a stitch row to keep the majority of the structure intact. This method of introducing an integral redundancy into the structure will permit higher operating strain

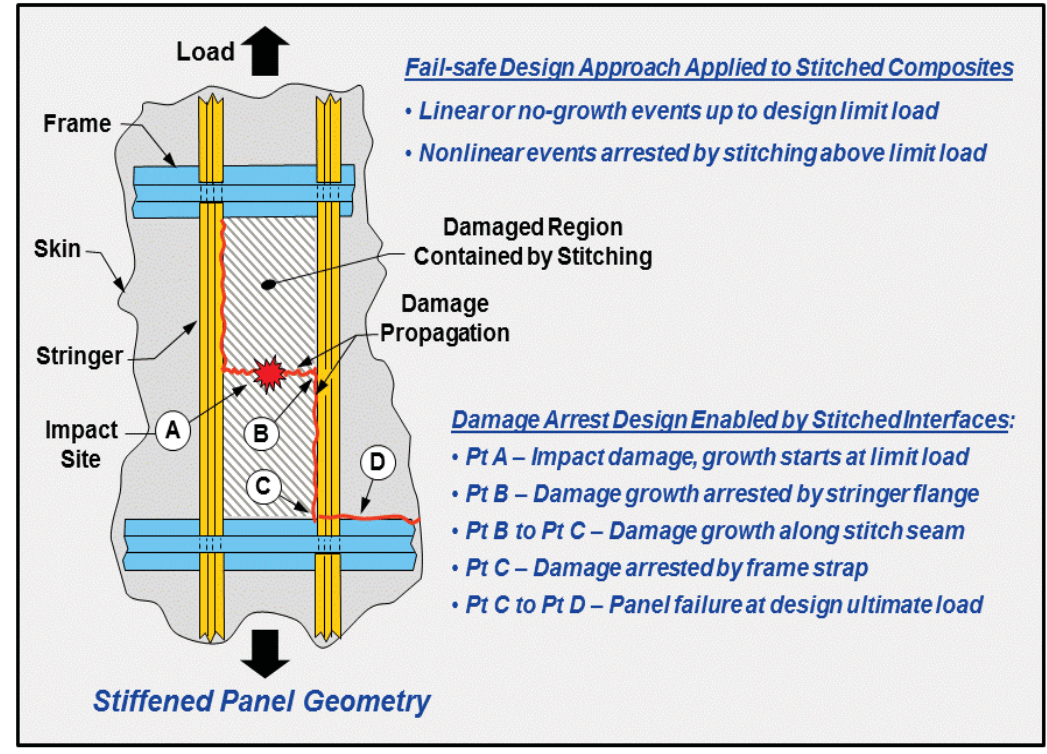

Figure 10. Damage-arrrest design approach to reduce panel weight. levels than would otherwise be possible using conventional unreinforced composite materials.

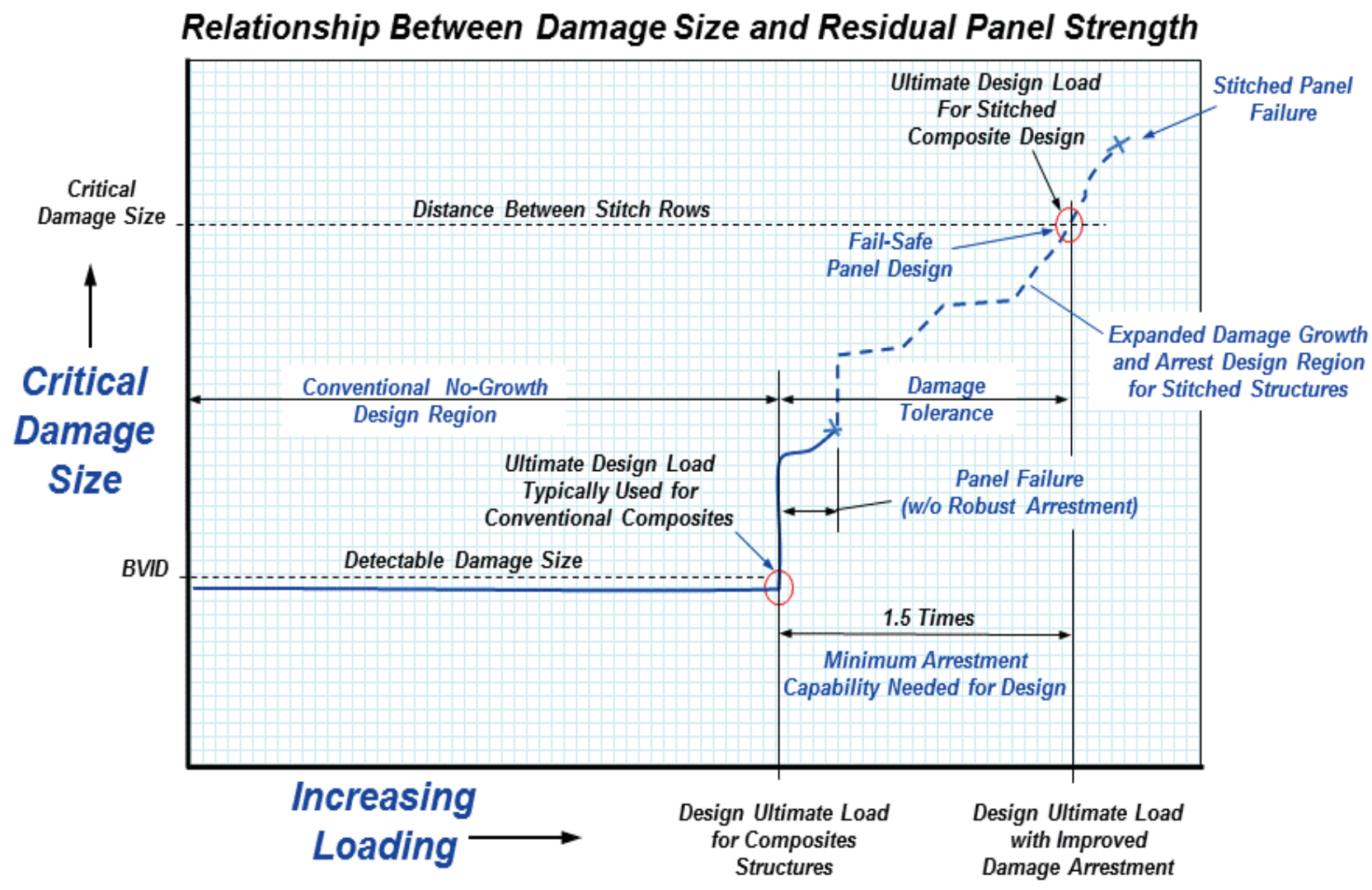

Figure 11. Stitching can be used to increase critical damage sizes beyond BVID design levels which would permit higher design strains that result in lighter weight panel designs. 


\section{B. Panel Repair Demonstrations}

As with any structural concept, as excess margins are driven out and the concept becomes more integrated, repairing the structure becomes more difficult. This generalization holds true for the highly optimized PRSEUS concept and is somewhat exacerbated by the use of the pultruded rod. To address this concern, a series of bolted repair specimen tests (Fig. 12) was conducted under tensile and bending load conditions. ${ }^{13-15}$

In each test, the bolted repair substantially exceeded the design ultimate load requirement. Tension-loaded panels failed outside of the repaired regions (suggesting specimens with reduced edge effects would have generated even higher values) and the pressure-loaded panel supported 30 psi without failing. The results showed that even the severed rod stiffened stringers were easily repaired using mechanically attached details that were capable of moving load
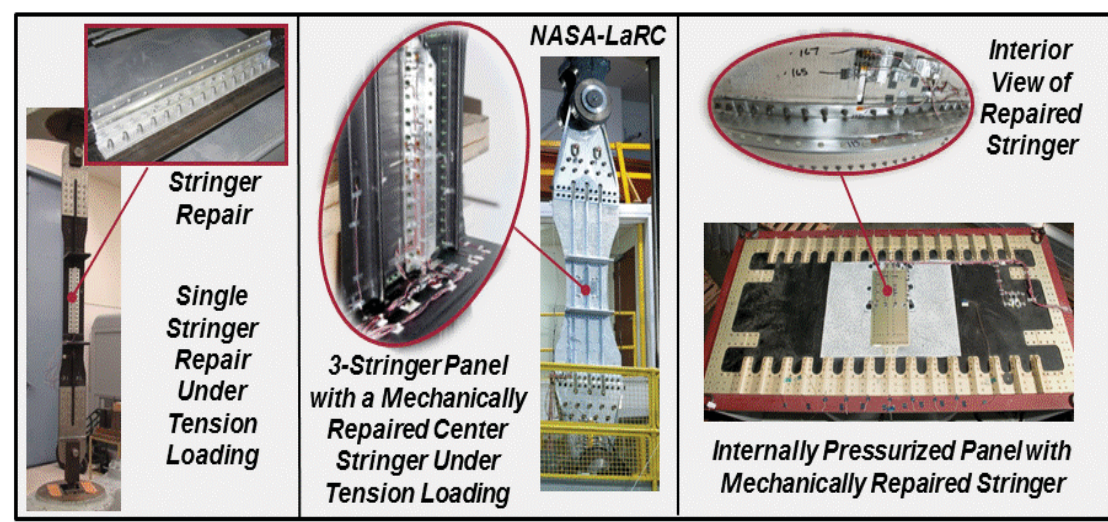

Figure 12. Testing to demonstrate bolted repair design approach.

away from the damaged regions and then redistributing it back into the undamaged sections of the panel through the repair fasteners.

\section{Demonstrating Panel Stability Under Compressive Loading}

The initial trade studies showed that the unitized design features of the PRSEUS skin and stiffening elements would have a favorable effect on the column stability of the panel. When comparing the normalized section stiffness parameter (EI) of common panel concepts (Fig. 13), the effectiveness of the pultruded rod was clearly evident. Whereas the I-stiffener and PRSEUS panels are more nearly equal, the absence of an interior stringer flange for the blade stiffener leads to a substantial weight penalty to maintain an equivalent value for the section stiffness.

In this example for a thin gauge panel, both the I-stiffener and PRSEUS stiffeners are able to maximize their section stiffness by placing material as far away as possible from the neutral axis. The I-stiffener does this by efficiently placing flange material at the extreme edges of the stiffener envelope, while the PRSEUS stiffener accomplishes the same effect by employing the higher modulus rod. The net effect is that I-stiffener structural efficiencies can be matched using a lower cost blade geometry by employing the PRSEUS rod

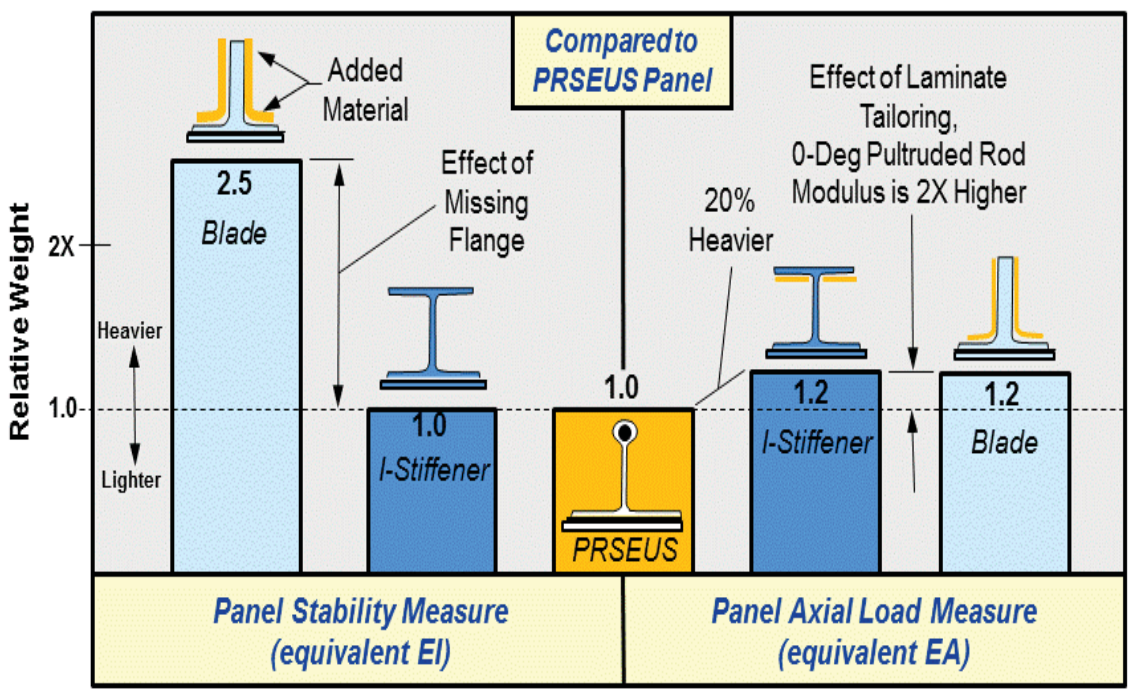

Figure 13. Normalized comparison of panel section properties. stiffened architecture.

To demonstrate the structural stability of the PRSEUS stringer, a building-block analysis and testing effort (Fig. 14) was undertaken that would quantify the benefits of having highly tailored stiffeners stitched directly to the skin, under both local and global buckling constraints. ${ }^{16-22}$ The column stability of the panels was first demonstrated using a series of single-stringer compression elements. The test results are graphically depicted in the load-vs-strain plot in Figure 15. Here, the data was plotted to show the failure loads relative to the nominal compressive strength-based design strains. The design goal for the test panels was to exceed the compression strength design 


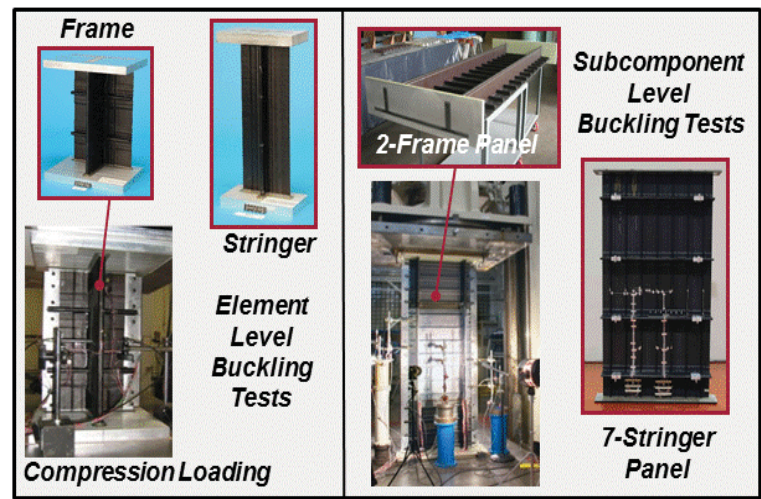

Figure 14. Testing to demonstrate local and global panel stability characterics.

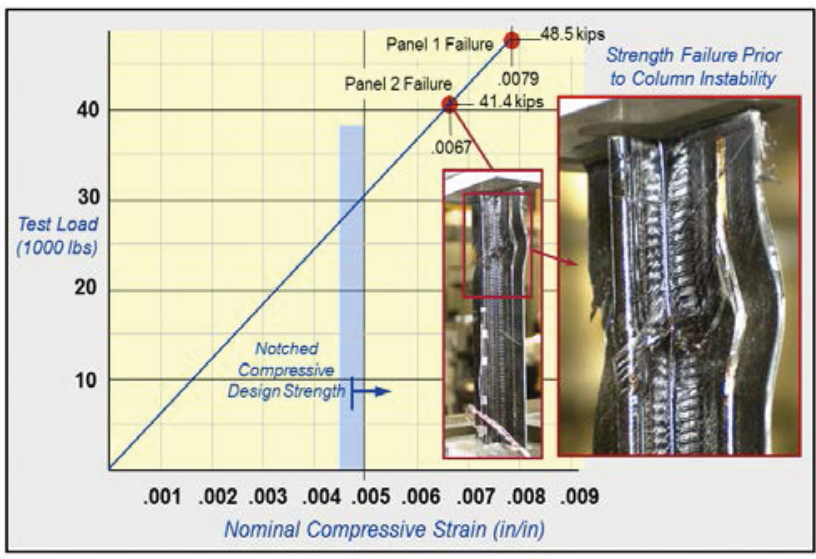

Figure 15. Plot of single-stringer test results.

allowable (0.0048 in/in in this case) prior to inducing a buckling mode failure. In both cases, strength-induced failures occurred at strains greater than the design allowable, before a column instability mode could be reached. These results demonstrated the superior column stability of the PRSEUS stringer cross-section as even the slender column compression specimens were not stability critical. ${ }^{16,20,21}$

Next, a compression test of a 7-stringer panel (Fig. 16) was conducted to assess the overall global panel buckling modes. The panel with a minimum gauge skin was loaded in compression to failure. Side supports on the unloaded edges and supports at the frames prevented the panel from entering a global buckling mode. However, numerous buckles occurred in the skin bays between the stiffeners. The changes in the strain and displacement patterns indicate that the stringers continued to support load well into the post-buckled range. ${ }^{12,22}$

The compression loading capability of the integral frame design was also investigated to determine its effectiveness under the span-wise loadings that would be prevalent in a Hybrid Wing Body (HWB) fuselage. When comparing a PRSEUS frame geometry to a

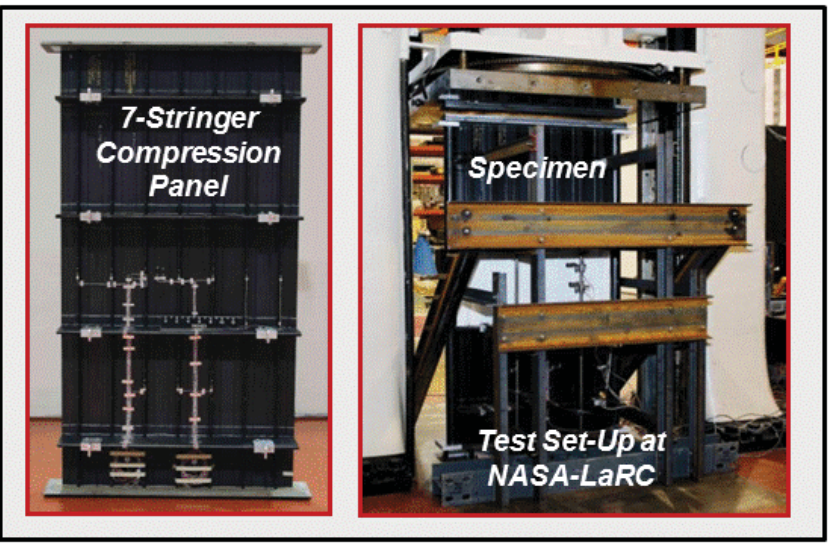

Figure 16. 7-stringer compression panel test. conventional design, there are two primary differences: 1) a taller frame height which affects the buckling and bending capability, and 2) the absence of a shear tie which eliminates the clip itself, the fasteners, and the asymmetry of the section. Incorporating these differences into the design leads to a more efficient material distribution and placement of the neutral axis which ultimately improves the overall section stiffness making the frame more stable under compression loading. (Fig. 17)

To test this hypothesis, single-frame specimens were subjected to unidirectional compressive loading to failure, while strains and displacements were recorded. A single-frame specimen prior to testing and after failure is shown in Figure 18 and described more thoroughly in Reference 20. The short columns remained stable until net-section strength failures occurred at the stringer cutouts in the frame webs where the frame area is the smallest.

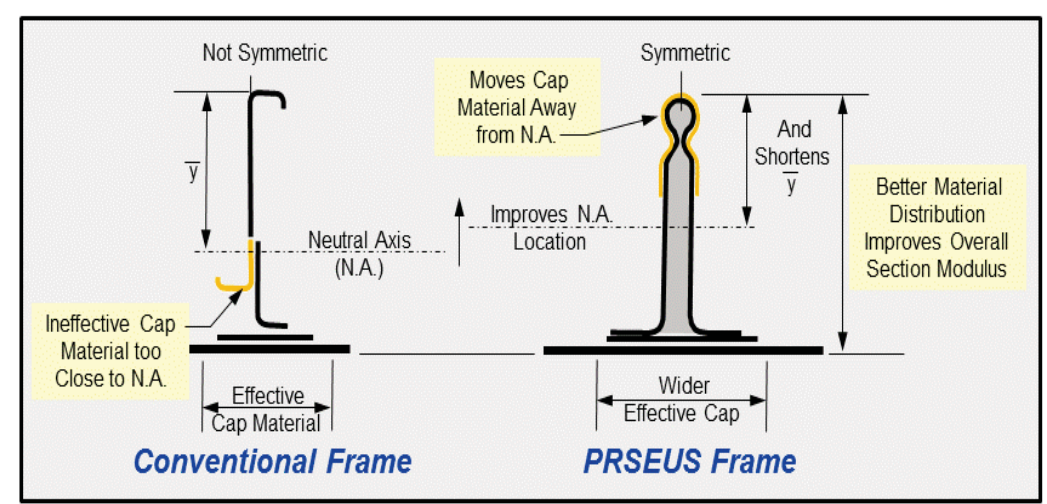

Figure 17. PRSEUS frame compared to built-up design. 
These results were then used to design a longer 2-frame compression panel which was tested to failure. Although local skin bucking between the stiffeners occurred at 23,000 lbs, the panel continued to support loading to approximately 147,000 lbs until a strength-based failure occurred at the stringer pass-through keyhole cutout location. The presence of high strains at the panel edges and in the frame webs at the stringer-frame intersections above Stringer 10 precipitated a strength failure prior to the observation of panel buckling. (Fig. 19)

Frame displacement measurements indicated little deformation for loads less than 120,000 lbs, with no sign of global buckling prior to the

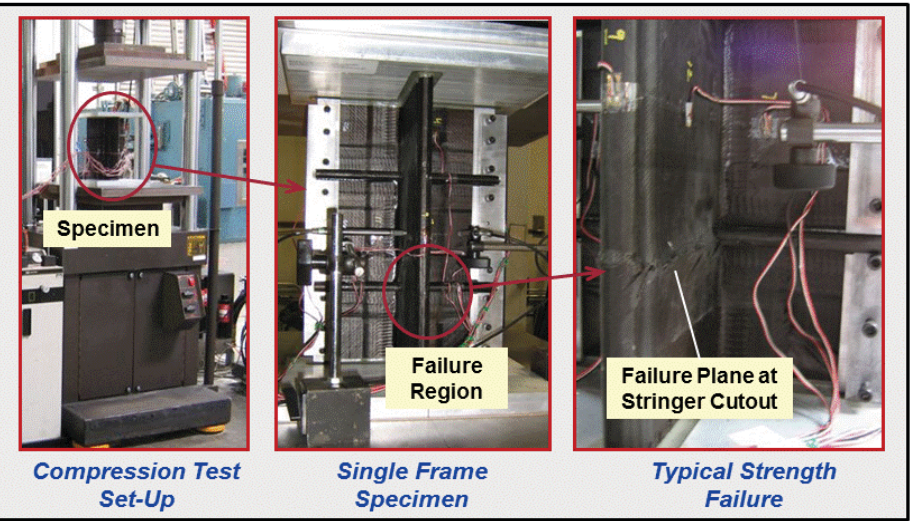

Figure 18. Single-frame element compression test. strength failure which occurred at 147,000 lbs. This result indicates that the panel withstood approximately six times the local buckling load prior to failure, or approximately 73,000 lbs per frame, and ultimately exceeded the allowable material strength before encountering a general panel buckling mode. The final failure runs through a keyhole in both frames, under the restraints and to the edge of the panel, seemingly connecting the locations of peak strains predicted by the FEM-based analysis, as well as those recorded by the video displacement system. ${ }^{18,19}$

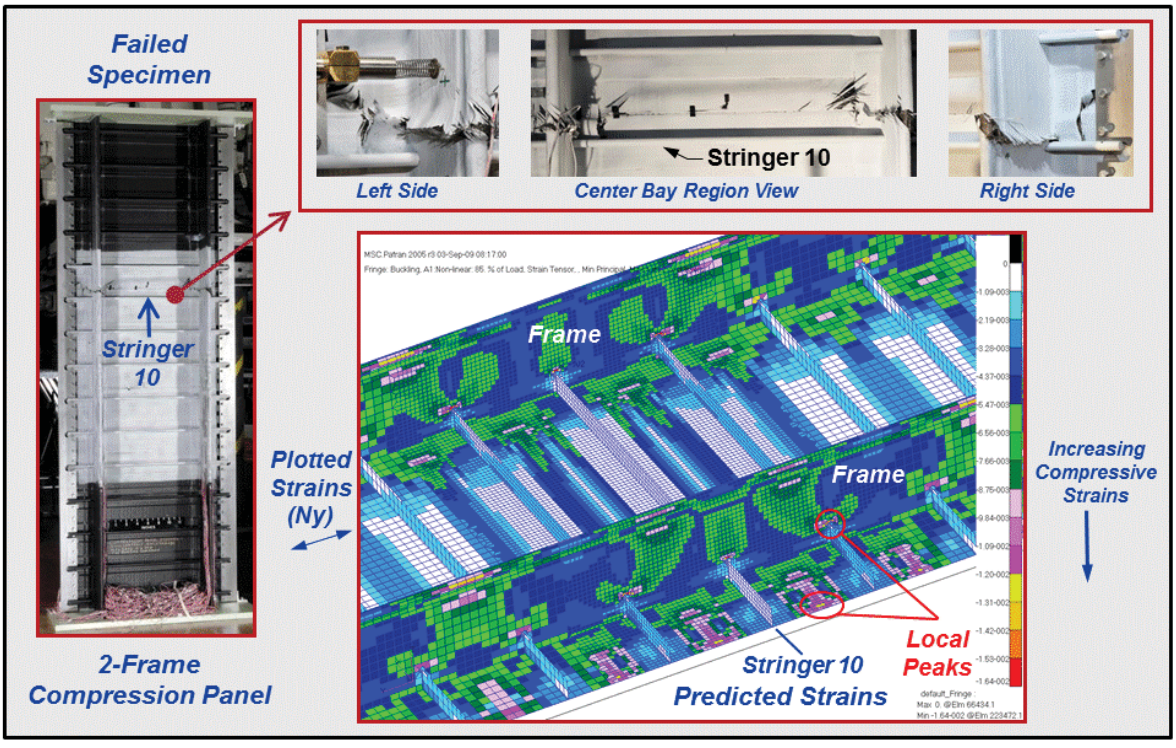

Figure 19. 2-frame compresson panel results.

\section{Assessing Key Structural Features}

The ability to eliminate mechanical attachments from the field of the panel and provide through-thickness reinforcement using stitching provides some unique advantages for the PRSEUS panel construction. Further development and testing (Fig. 20) in the areas of acoustic transmission, ${ }^{23-25}$ ultrasonic inspection, ${ }^{26}$ rod-to-wrap adhesion, ${ }^{27}$ local stringer-frame intersection behavior, ${ }^{28}$ response under internal pressure loading, ${ }^{29}$ and integral panel-to-panel attachment ${ }^{30,31}$ were also undertaken to quantify these benefits. The largest of these efforts was the cube subcomponent development specimen which was undertaken to address the difficult structural transitions encountered in the flat-sided pressure panels that are

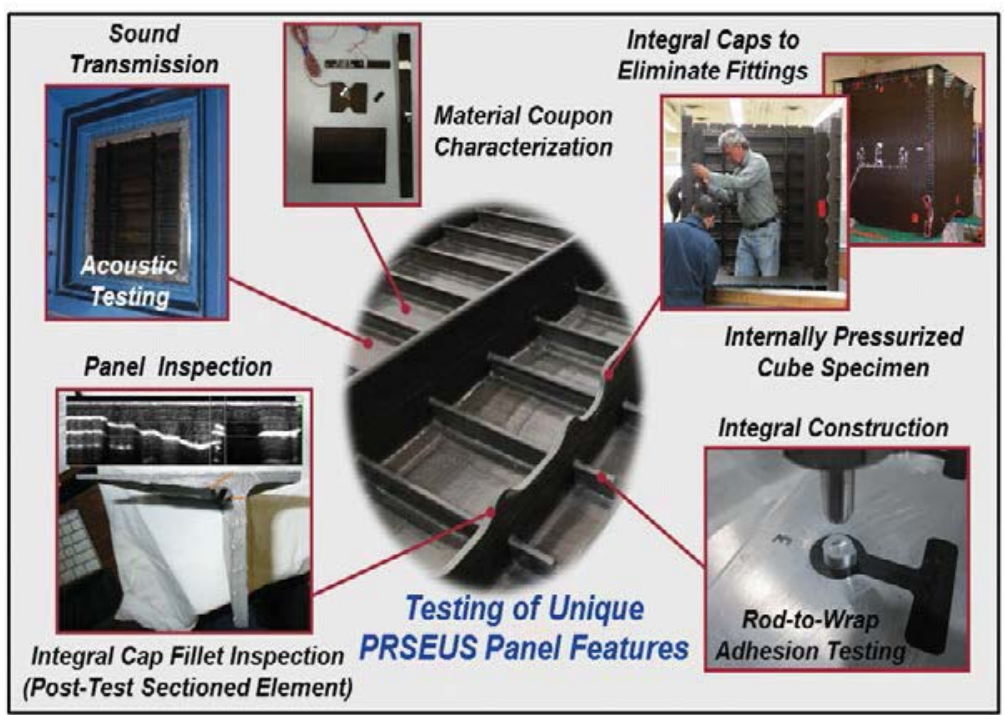

Figure 20. Testing of unique PRSEUS design features. 
representative of the HWB pressure cabin. The test article was constructed of six PRSEUS panel assemblies that were bolted together at the edges to create a pressure tight cube (Fig. 21). The test article was then tested in an over-pressure condition to simulate an equivalent bending moment in the corners as would be encountered in a full-sized structure.

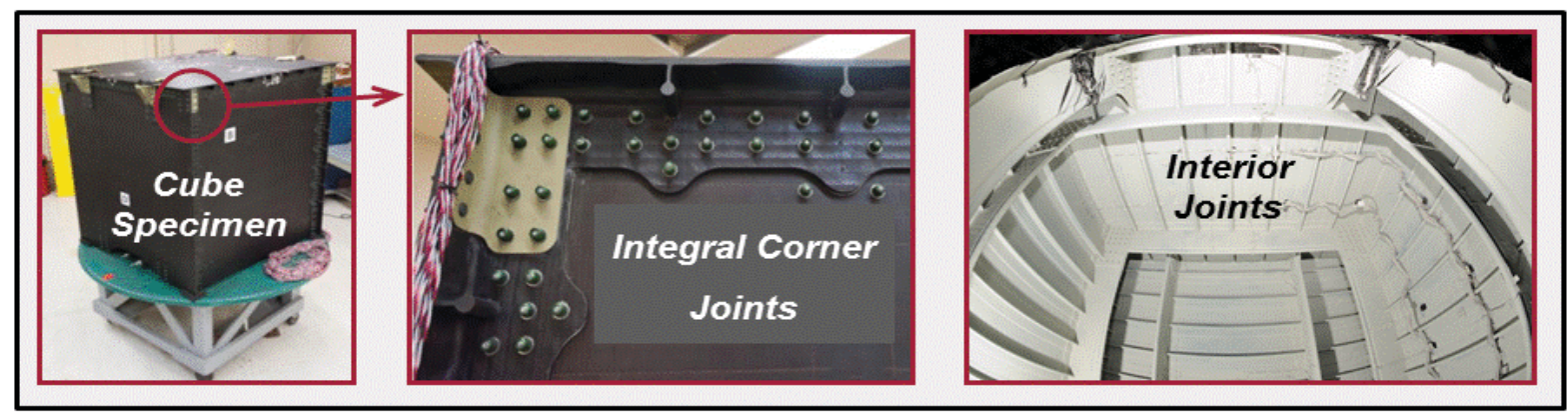

Figure 21. Cube test article demonstrated integral panel-to-panel joining features.

The cube specimen exceeded the maximum bending moment requirement before an internal aluminum splice fitting failed at 48 psi internal pressure loading. This result validated that the integral cap design used to join the panels would be capable of meeting the higher loading requirements of a larger, or scaled-up flat-sided pressure vessel. ${ }^{30,31}$

\section{E. Fabrication Scale-Up}

One of the principal discriminators for the PRSEUS fabrication technology was to demonstrate that a collection of stitched dry fabric can be infused and cured in an oven and still result in lower recurring fabrication costs than conventional composite processes. The PRSEUS fabrication sequence (Fig. 22), starts with the cutting of individual pieces of warp-knit fabric on a cutting table, which are then organized into kits. Precured rods and foam-core details

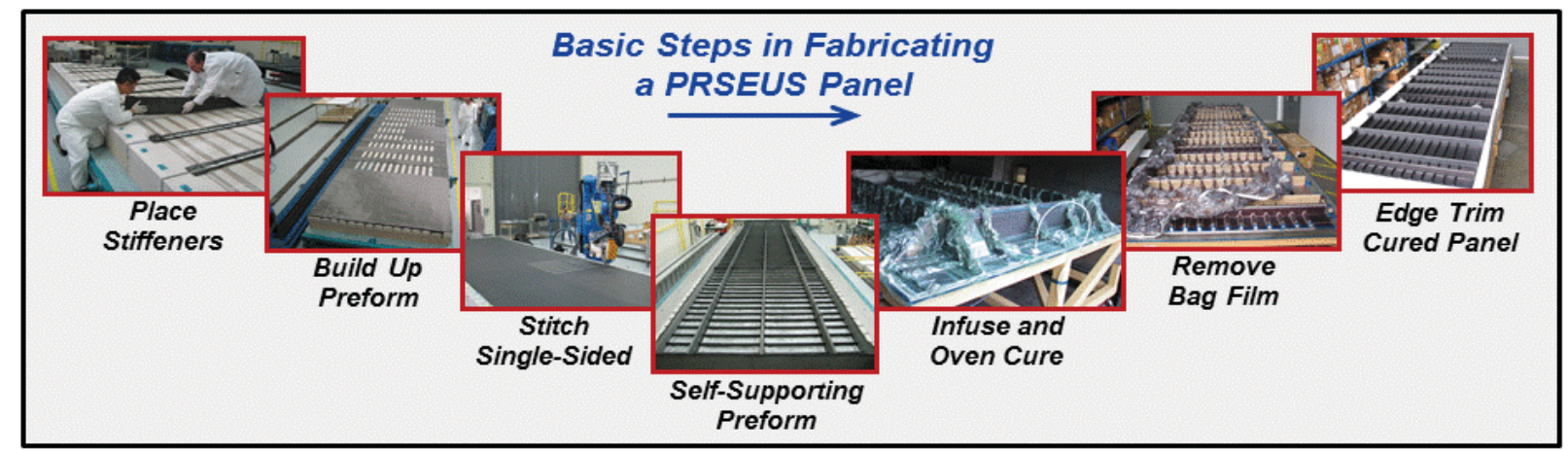

Figure 22. Basic steps to fabricate a PRSEUS panel.

are also prepared and in some cases, assembled into smaller pre-stitched assemblies. All of these details are then delivered to the preform assembly fixture where they are properly positioned, and then stitched in place to create a self-supporting dry carbon preform.

The preform is then transferred to an outer mold line cure tool for resin infusion processing where a pleated nylon vacuum bag system is placed directly over the preform and sealed down against the cure tool edges. The preform is then infused with resin and cured using an out-of-autoclave process. The initial cure takes place at $250^{\circ} \mathrm{F}$, followed by vacuum bag and resin line removal, and then a $350^{\circ} \mathrm{F}$ free-standing post-cure. The completed panel assembly like the one pictured in Figure 23 would then be ready for a final edge-trim machining operation.

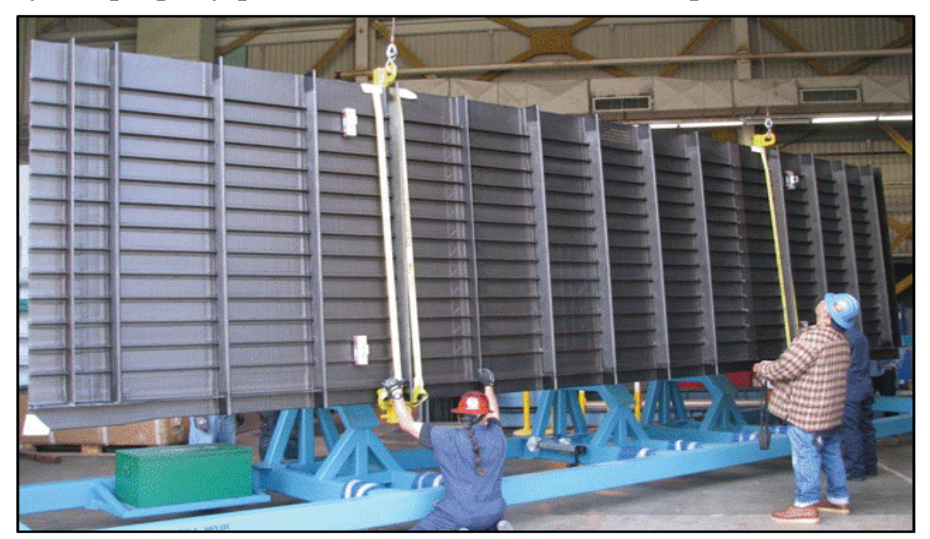

Figure 23. Cured PRSEUS prior to edge machining.

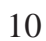

American Institute of Aeronautics and Astronautics 
The completed panel assemblies are mechanically joined together using the integral cap feature to reduce the number of metal fittings and eliminate fasteners through the exterior surface of the panel. As such, the fasteners are loaded in shear and any pull-off loading is reacted directly into the adjacent panel through the stitched integral cap members. The absence of extraneous hardware in the panel-to-panel connections is clearly evident in Figure 24, resulting in fewer parts, less drilling, less lightning strike protection materials, and ultimately lower recurring costs.

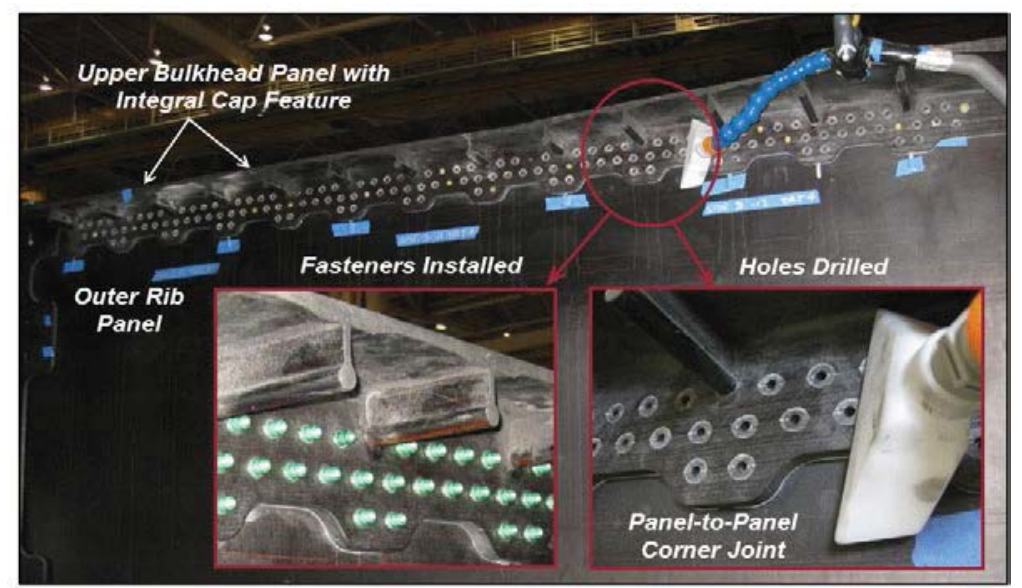

Figure 24. Integral cap features are used to simplify joining.

Since the first PRSEUS panel was successfully fabricated in 2006 (Fig. 25), the manufacturing technologies necessary to support new stitching, tooling, resin infusion, and panel assembly techniques have been rapidly matured in the lab to deliver ever-increasing levels of panel complexity, quality, and size to the point where meeting production level quality standards are now routine. Although many detail processing improvements have been made along the way, the core principle first proposed for the PRSEUS concept, creating a self-supporting preform that could be infused with resin without internal tooling, has been thoroughly demonstrated and is now ready for the next phase of implementation where the individual processes and equipment would be industrialized to further optimize the low recurring costs that are being realized within the lab setting.

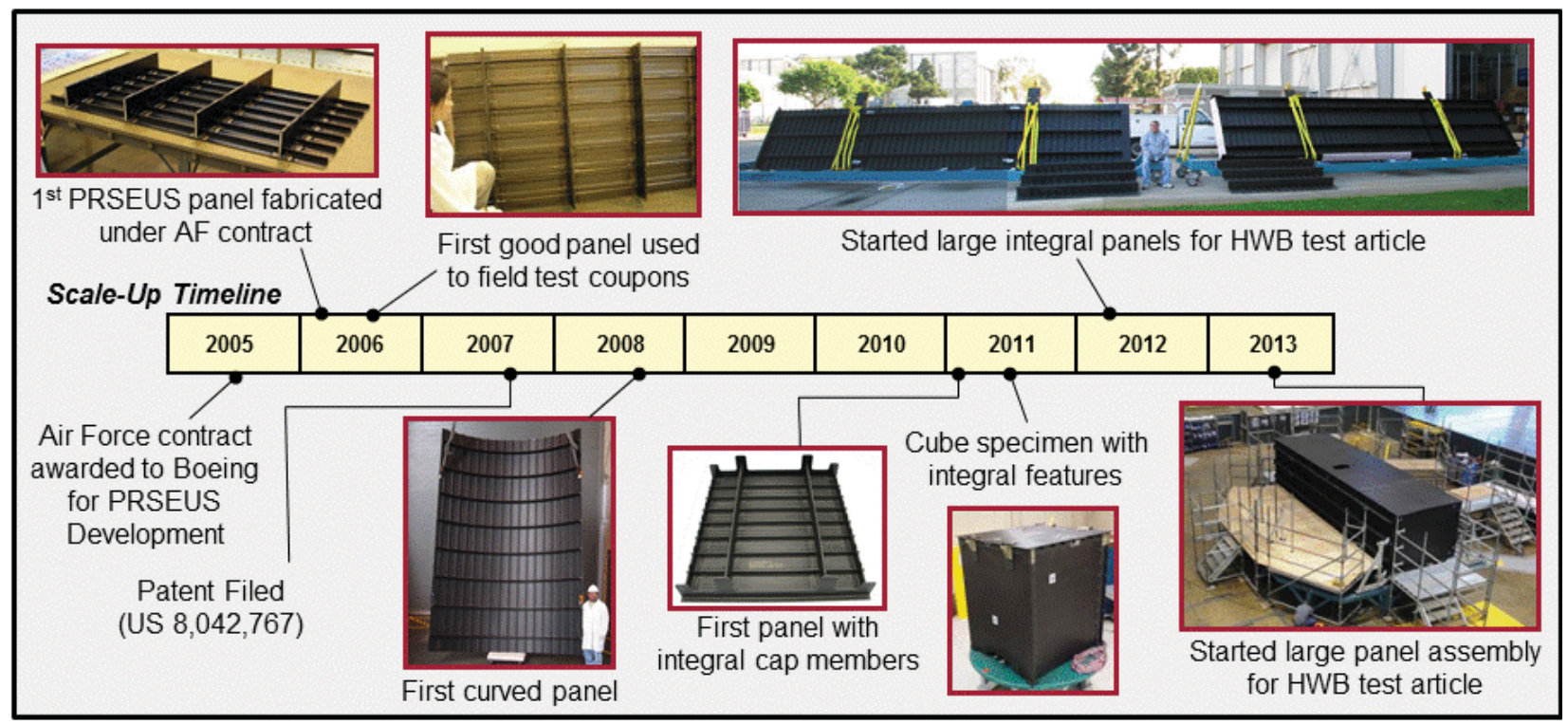

Figure 25. PRSEUS manufacturing development timeline.

\section{Future Work}

From the initial trade studies used to establish design parameters, characterization of the PRSEUS concept continues to take shape in the context of the HWB research where coordinated research work is being performed by NASA and Boeing researchers under the NASA Environmentally Responsible Aviation Project. This work has produced a series of keystone tests that have demonstrated that the PRSEUS panel assembly is capable of meeting the unique tension, compression, and pressure loading conditions of the HWB pressure cabin. The knowledge gained from these tests is being used to develop the large scale multi-bay box test article that will be tested at NASA-LaRC in the Combined Loads Test System (COLTS) in 2015. (Fig. 26) Here, a 30-foot long double-deck 
closed-box structure will be subjected to a combined bending plus internal pressure loading environment representative of an HWB fuselage design envelope. ${ }^{32-36}$

\section{Concluding Remarks}

The PRSEUS panel architecture was conceived to address the weight and cost short-comings inherent in conventional layered material systems. By replacing pre-impregnated materials with dry fabric, and fasteners with stitching, a highly engineered structural solution is possible that moves beyond traditional composite design practices to offer a highly integrated structural solution with better load paths, higher levels of fiber tailoring, and the ability to stop damage progression. By conducting a

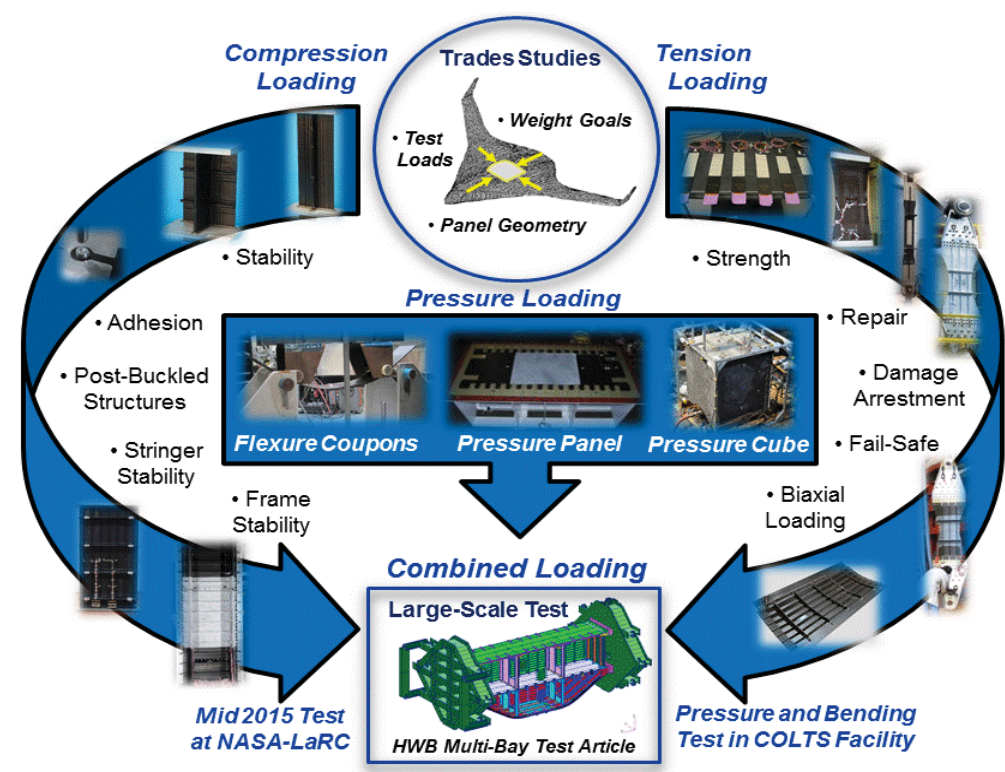

Figure 26. Development path leading to HWB large-scale test article. series of representative tests, it has been demonstrated that this new approach is capable of efficiently operating within the design space of transport aircraft wing and fuselage applications. Characterization of this innovative approach continues to take shape in the context of the HWB research where coordinated research work is being performed by NASA and Boeing researchers under the NASA Environmentally Responsible Aviation Project.

\section{References}

${ }^{1}$ Velicki A., and Thrash P.J., “Advanced Structural Concept Development Using Stitched Composites,” 49th AIAA/ASME/ASCE/AHS/ASC Structures, Structural Dynamics, and Materials Conference, Paper Number AIAA-2008-2329, June 2008, Schaumburg, IL.

${ }^{2}$ Jegley, D.C., and Velicki, A., “Status of Advanced Stitched Composite Aircraft Structure,” presentation only, 49th AIAA Sciences Meeting, Integrated Systems Research Program Technical Session, Jan 6-9 2011, Orlando, FL.

${ }^{3}$ Jegley, D.C., and Velicki, A., “Status of Advanced Stitched Unitized Composite Aircraft Structure," 51st AIAA Sciences Meeting, Environmentally Responsible Aviation Progress I Technical Session, paper Number AIAA 2013-0410, Jan 7-10 2013, Grapevine, TX.

${ }^{4}$ Velicki, A., “Damage Arrest Design Approach with Composite Materials,” presentation only, Aging Aircraft 2009 Conference, Kansas City Convention Center, May 4 - 7, 2009.

${ }^{5}$ Velicki, A., and Thrash, P.J., "Damage Arrest Design Approach Using Stitched Composites,” 2nd Aircraft Structural Design Conference, Tuesday 26 - Thursday 28 October 2010, No.4 Hamilton Place, London, UK.

${ }^{6}$ Velicki, A., and Thrash, P.J., "Damage Arrest Design Approach Using Stitched Composites," The Aeronautical Journal, December 2011, Volume 115, Number 1174, pages 789-795, Royal Aeronautical Society, London, UK.

${ }^{7}$ Bergen, A., Bakuckas, J., Lovejoy, A., Jegley, D., Linton, K., Korkosz, G., Awerbuch, J., Tan, T., "Full-Scale Test and Analysis of a PRSEUS Fuselage Panel to Assess Damage-Containment Features” , Aircraft Airworthiness \& Sustainment Conference 2011, paper Number TP4558, 20 April 2011, San Diego, CA.

${ }^{8}$ Bergen, A., Bakuckas, J., Lovejoy, A., Jegley, D., Linton, K., Neal, A., Korkosz, G., Awerbuch, J., Tan, T., "Full-scale Test and Analysis Results of a PRSEUS Fuselage Panel to Assess Damage-Containment Features,” 2012 Aircraft Airworthiness \& Sustainment Conference, paper Number TP5430, 1-5 April 2012, Baltimore, MD.

${ }^{9}$ Bergen, A., Bakuckas, J., Lovejoy, A., Jegley, D., Awerbuch, J., Tan, T., “Assessment of Damage-Containment Features of a Full-scale PRSEUS Fuselage Panel through Test and Teardown,” American Society for Composites 27th Technical Conference Oct 1-3, 2012, Arlington, TX.

${ }^{10}$ Gould, K., Lovejoy, A., Neal, A., Linton, K., Bergan, A., and Bakuckas Jr, J., "Nonlinear Analysis and Post-Test Correlation for a Curved PRSEUS Panel," 54th AIAA Structures, Structural Dynamics, and Materials Conference, paper Number AIAA-2013-1736, 8-11 April 2013, Boston, MA.

${ }^{11}$ Bakuckas Jr, J., Bergan, A., and Jegley, D., "Demonstration of PRSEUS Concept for Fuselage Panel Applications - An Overview,” 27th ICAF Symposium, June 5-7, 2013, Jerusalem, Israel.

${ }^{12}$ Jegley, D., "Structural Efficiency and Behavior of Pristine and Notched Stitched Structure," presented at SAMPE Fall Technical Conference, Oct. 2011, Fort Worth. TX. 
${ }^{13}$ Przekop, A., “Design and Analysis of a Stiffened Composite Structure Repair Concept,” 52th AIAA Structures Dynamics and Materials Conference, paper Number AIAA-2011-1912, 5 April 2011, Denver, CO.

${ }^{14}$ Przekop, A., and Jegley, D., “Testing and Analysis Validation of a Metallic Repair Applied to a PRSEUS Tension Panel,” 54th AIAA Structures, Structural Dynamics, and Materials Conference, paper Number AIAA-2013-1735, 8-11 April 2013, Boston, MA.

${ }^{15}$ Lovejoy, A. and Poplawski, S., "Preliminary Design and Analysis of an In-plane PRSEUS Joint “, 54th AIAA Structures, Structural Dynamics, and Materials Conference, paper Number AIAA-2013-1737, 8-11 April 2013, Boston, MA.

${ }^{16}$ Jegley, D.C., Velicki, A., Hansen, D., "Structural Efficiency Of Stitched Rod-stiffened Composite Panels With Stiffener Crippling,” 49th AIAA/ASME/ASCE/SHS/ASC Structures, Structural Dynamics, and Materials Conference, 7-10 April 2008, Schaumburg, IL.

${ }^{17}$ Yovanof, N.P., “Advanced Structural Stability of a Non-Circular BWB-Shaped Vehicle,” 50th AIAA Structures Dynamics and Materials Conference, May 4-7 2009, Palm Springs, CA.

${ }^{18}$ Yovanof, N., and Jegley, D., "Compressive Behavior of Frame-Stiffened Composite Panels," 52th AIAA Structures Dynamics and Materials Conference, paper Number AIAA-2011-1913, 5 April 2011, Denver, CO.

${ }^{19}$ Jegley, D., "Behavior of Frame-Stiffened Composite Panels with Damage," 54th AIAA Structures, Structural Dynamics, and Materials Conference, paper Number AIAA-2013-1738, 811 April 2013, Boston, MA.

${ }^{20}$ Velicki, A., “Damage Arresting Composites for Shaped Vehicles-Phase I Final Report,” NASA CR-2009-215932, Sept 2009.

${ }^{21}$ Jegley, D., “Experimental Behavior of Fatigued Single Stiffener PRSEUS Specimens,” NASA TM-2009-215955, Dec. 2009.

${ }^{22}$ Jegley, D., “The Influence of Restraint Systems on Panel Behavior,” presented at Society of Experimental Mechanics Conference, Mohegan Sun, Uncasville, Conn., June 2011.

${ }^{23}$ Allen, A., and Przekop, A., "Vibroacoustic Characterization of a New Hybrid Wing-Body Fuselage Concept," INTERNOISE 2012 Conference, 2012 August 19-22, New York City, USA.

${ }^{24}$ Khanolkar, A., Bergan, A., Ozevin, Awerbuch, J., and Tan, T., Monitoring Acoustic Emissions in a PRSEUS Fuselage Panel Under Combined Loading,” American Society for Composites 27th Technical Conference Oct 1-3, 2012, Arlington, TX.

${ }^{25}$ Horne, M. and Maderas, E., "Evaluation of Acoustic Emission SHM of PRSEUS Composite Pressure Cube Tests,” NASA TM 2013-217993, May 2013.

${ }^{26}$ Johnston, P., "Ultrasonic Nondestructive Evaluation of PRSEUS Pressure Cube Article in Support of Load Test to Failure," NASA TM 2013-217799, May 2013.

${ }^{27}$ Wang, J., Grenoble, R., and Pickell, R., "Structural Integrity Testing Method for PRSEUS Rod-Wrap Stringer Design,” 53rd AIAA Structures, Structural Dynamics, and Materials Conference, paper Number AIAA-2012-1861, April 2012, Honolulu, HI.

${ }^{28}$ Jegley, D. "Failure at Frame-Stringer Intersections in PRSEUS Panels,” American Society for Composites 27th Technical Conference Oct 1-3, 2012, Arlington, TX.

${ }^{29}$ Lovejoy, A., Rouse, M., Linton, K., and Li, V., "Pressure Testing of a Minimum Gauge PRSEUS Panel," 52th AIAA Structures Dynamics and Materials Conference, paper Number AIAA-2011-1813, 4 April 2011, Denver, CO.

${ }^{30}$ Yovanof, N., Baraja, J, Lovejoy, A., Gould, K., "Design, Analysis, and Testing of a PRSEUS Pressure Cube to Investigate Assembly Joints,” 2012 Aircraft Airworthiness \& Sustainment Conference, paper Number TP5431, 1-5 April 2012, Baltimore, MD.

${ }^{31}$ Lovejoy, A., “PRSEUS Pressure Cube Test Data and Response,” NASA TM 2013-217795, May 2013.

${ }^{32} \mathrm{Li}$, V., and Velicki, A., "Advanced PRSEUS Structural Concept Design and Optimization," 12th AIAA/ISSMO Multidisciplinary Analysis and Optimization Conference, AIAA-2008-5840, Sept. 10-12 2008, Victoria, British Columbia, Canada.

${ }^{33}$ Velicki A., and Thrash P.J., "Blended Wing Body Structural Concept Development,” Aircraft Structural Design Conference, Oct 14-16 2008, Liverpool, UK.

${ }^{34}$ Velicki A., Jegley, D.C., and Thrash P.J., “Airframe Development for the Hybrid Wing Body Aircraft,” 47th AIAA Sciences Meeting, AIAA-2009-932, Jan 5-8 2009, Orlando, FL.

${ }^{35}$ Velicki, A., and Thrash, P.J., "Blended Wing Body Structural Concept Development,” The Aeronautical Journal, August 2010, Volume 114, Number 1158, paper 3392, Royal Aeronautical Society, London, UK.

${ }^{36}$ Wu, H.T., Shaw, P., and Przekop, A., "Analysis of a Hybrid Wing Body Center Section Test Article," 54th AIAA Structures, Structural Dynamics, and Materials Conference, paper Number AIAA-2013-1734, 8-11 April 2013, Boston, MA. 